$$
\begin{array}{lc}
\text { CONF-9610202-2 } & \text { RECEIVED } \\
\text { ANL/ET/CP--91433 } & \text { NOV } 051996 \\
\text { OSTI }
\end{array}
$$

Overview of Steam Generator Tube Degradation and Integrity Issues*

by

D. R. Diercks ${ }^{\dagger}$, W. J. Shack ${ }^{\dagger}$, and J. Muscara,**

${ }^{\dagger}$ Energy Technology Division

Argonne National Laboratory

Argonne, Illinois 60439

**Office of Nuclear Regulatory Research

U.S. Nuclear Regulatory Commission

Washington, DC 20555

October 1996

The submitted manuscript has been authored

by a contractor of the $U$.-S. Government

under contract No. W-31-109ENG-38.

Accordingly, the U.S. Government retains a

nonexclusive, royalty-free license to publish

or reproduce the published form of this

contribution, or allow others to do so, for

U. S. Government purposes.

Submitted for publication in the Proc. of the 24th Water Reactor Safety Meeting, Bethesda, MD, October 21-23, 1996.

*Work supported by the Office of Nuclear Regulatory Research, U.S. Nuclear Regulatory Commission. 


\section{DISCLAIMER}

Portions of this document may be illegible in electronic image products. Images are produced from the best available original document. 


\title{
Overview of Steam Generator Tube Degradation and Integrity Issues*
}

\author{
D. R. Diercks, W. J. Shack, and J. Muscara** \\ Argonne National Laboratory \\ Argonne, IL \\ ** Office of Nuclear Regulatory Research, USNRC
}

\section{Abstract}

The degradation of steam generator tubes in pressurized water nuclear reactors, particularly by stress corrosion cracking mechanisms, continues to be a serious problem. Primary water stress corrosion cracking is commonly observed at the roll transition zone at U-bends, at tube denting locations, and occasionally in plugs and sleeves. Outer-diameter stress corrosion cracking and intergranular attack commonly occur near the tube support plate crevice, near the tube sheet in crevices or under sludge piles, and occasionally in the free span. A particularly troubling recent trend has been the increasing occurrence of circumferential cracking at the RTZ on both the primary and secondary sides. Segmented axial cracking at the tubes support plate crevices, with interspersed uncracked ligaments, is also becoming more common. Despite recent advances in in-service inspection technology, a clear need still exists for quantifying and improving the reliability of in-service inspection methods with respect to the probability of detection of the various types of flaws and their accurate sizing. These improvements are necessary to permit an accurate assessment of the consequences of leaving degraded tubes in service over the next reactor operating cycle.

Improved inspection technology and the increasing occurrence of such degradation modes as circumferential cracking, intergranular attack, and discontinuous axial cracking have led to the formulation of a new performancebased steam generator rule. This new rule would require the development and 
implementation of a steam generator management program that monitors tube condition against accepted performance criteria to ensure that the tubes perform the required safety function over the next operating cycle. The new steam generator rule will also be applied to severe accident conditions to determine the continued serviceability of a steam generator with degraded tubes in the event of a severe accident. Preliminary analyses are being performed for a hypothetical severe accident scenario to determine whether failure will occur first in the steam generator tubes, which would lead to containment bypass, or instead in the hot leg nozzle or surge line, which would not.

*Job code: W6487; NRC Program Manager: Dr. J. Muscara 


\section{Introduction}

Reliability problems have plagued steam generators since the very introduction of commercial pressurized water reactor technology in the late 1950 's. Various forms of steam generator tube degradation have resulted in the plugging of more than 100,000 tubes to date around the world. 1 In $1994,49 \%$ of the 217 operating PWRs included in the annual EPRI report on the worldwide status of steam generator problems were required to plug steam generator tubes. Sixty-one steam generators in 22 PWRs around the world had been replaced by the end of 1994 because of serious tubing degradation, including 35 steam generators at 12 plants in the U.S. The replacement of 85 additional steam generators at 27 plants worldwide was planned, with 33 of these steam generators located at 10 plants in the U.S. 1 The cost associated with such steam generator replacements now typically ranges between $\$ 100$ million and $\$ 200$ million per plant, not including power replacement costs. 2

The causes of steam generator tube plugging have evolved with time, as shown in Fig. 1.1 Early problems with wastage were found to be associated with the use of a low $\mathrm{Na} / \mathrm{PO}_{4}$ molar ratio phosphate water chemistry, and the problem was essentially eliminated with the introduction of all volatile secondary water treatment for $\mathrm{pH}$ control. Subsequent problems with tube denting were solved through better water purity, the replacement of $\mathrm{Cu}$ bearing alloys in the secondary system, and redesign of the tube support plates to eliminate the use of carbon steel and modify the geometries at the junctions with the tubes. Figure 1 clearly indicates that in recent years, primary water stress corrosion cracking (PWSCC) and outer diameter stress corrosion cracking and intergranular attack (ODSCC/IGA) have become the predominant identifiable causes of steam generator tube plugging in the U.S. The remainder of this paper will deal with these forms of tube degradation and their impact on tube integrity. 


\section{Corrosion Problems in Steam Generator Tubing}

As indicated above, stress corrosion cracking ( $\mathrm{SCC}$ ), both on the primary and secondary sides of the steam generator tubes, has become the principal degradation mode leading to tube plugging in the U.S. and worldwide. SCC can occur at any of a number of locations on both sides of the steam generator tubes, and it can take on variety of forms and configurations. The various forms of SCC seen and recent trends in observed degradation modes are summarized here.

\subsection{Primary Water Stress Corrosion Cracking}

\subsubsection{PWSCC in the Roll Transition Zone}

PWSCC most commonly occurs in the tube expansion transition region, or roll transition zone (RTZ), where the tube is expanded into the tube sheet. The cracks are usually axial, but circumferential cracking has also been observed and can occur near the end of the expanded region above the tube sheet or farther down in the expanded portion of the tube. This type of cracking is discussed in more detail in Section 2.3 In the latter location, the cracks pose no particular threat to tubing integrity as long as they are sufficiently contained within the tube sheet to preclude bursting. However, PWSCC is a serious problem and a leading cause of tube plugging when it occurs near the end of the expanded zone above the tube sheet.

Several processes have been used to expand and seal the tubes against the tube sheets, and the process used strongly influences the residual stresses present in the RTZ and the tendency toward PWSCC. The mechanical roll expansion process used by Westinghouse and its licensees for many years, in combination with low-temperature mill-annealed (LTMA) tube material, has led to a relatively high incidence of PWSCC in PWR steam generators. Reduced instances of PWSCC have been reported in tubes expanded by the Westinghouse 
explosive expansion (Wextex) process, and the most recent use of hydraulic expansion in Westinghouse steam generators has been demonstrated to produce lower residual stresses. Combustion Engineering plants use an explosive tube sheet expansion process ("Explansion") in combination with high-temperature mill-annealed (HTMA) tube material, and these units have only recently begun to experience PWSCC in the expansion zone. Babcock \& Wilcox units utilize mechanically expanded transitions that have been stress relieved and sensitized. These units do not appear to have experienced PWSCC, a circumstance that can be attributed at least in part to the beneficial microstructure produced by the heat treatment. A two-step roll transition configuration with less severe reductions ("kiss rolling") used in French ${ }^{3}$ and Belgian4 plants has experienced early axial cracking at both ends of the step. In any plant design regardless of fabrication process, fabrication errors such as oversize holes in the tube sheet, incomplete expansion, and overexpansion can increase the susceptibility to PWSCC. 5,6

\subsubsection{PWSCC at U-Bends}

The forming processes used to produce U-bends in steam generator tubes can create residual stresses in the bends, with the greatest stress levels occurring in the inner row tubes with the smallest radius of curvature. These stresses, in combination with a susceptible microstructure, can be sufficient to cause PWSCC problems. Historically, the first such problems were seen in the rows 1 and $2 \mathrm{U}-$ bends of earlier design Westinghouse 7 and Framatome ${ }^{8}$ units, where the U-bends were not stress relieved and the tubing material was LTMA Alloy 600. The problem was dealt with in a similar manner in both designs. In some cases, the most susceptible tubes were plugged as a preventative measure, but the subsequent development of an in-situ thermal treatment process appears to have solved the problem. ${ }^{8}$ Newer designs utilize thermally treated U-bends in combination with more resistant material (e.g., Alloy 600 TT or Alloy 690), and the problem has been largely eliminated. 


\subsubsection{PWSCC at Tube Denting Locations}

PWSCC has also been known to initiate at tube dents resulting from tube support plate (TSP) corrosion. This phenomenon has probably been most thoroughly documented in the examination of the retired Surry Unit 2A steam generator destructively examined at Pacific Northwest National Laboratory (PNNL) in the 1980s.9 A total of 27 hot leg and 11 cold leg dented tubes were examined for ID cracking. PWSCC was not observed in any of the tubes with denting strains below $10 \%$, in about one-third of the tubes with strains between 10 and $20 \%$, and in all of the tubes with strains $>20 \%$. Crack depths ranged from 27 to $88 \%$ of the wall thickness. Circumferential cracking at relatively mild TSP dent locations has also been observed in a few plants, as discussed in Section 2.3.

\subsubsection{PWSCC of Plugs and Sleeves}

PWSCC can also occur in the plugs used to remove steam generator tubes from service. Failures in both Westinghouse and Babcock \& Wilcox mechanical plugs have been reported ${ }^{10-15}$; the first reported failure of a Westinghouse plug occurred at North Anna Unit 1 in February of 1989, and plug cracking was subsequently detected at several other plants, including Sequoyah 1 and North Anna 2. It was concluded that the thermally treated Alloy 600 plugs were failing by PWSCC and that essentially all of them had come from one of four heats of susceptible material. Another susceptible heat has been more recently identified.14 In the case of the Babcock \& Wilcox plugs, cracking has been detected in several plants prior to gross failure, and a susceptible heat of Alloy 600 material was again implicated. 15

PWSCC of tube regions fitted with repair sleeves is also reported in the literature. ${ }^{16,17}$ Cracking typically occurs not in the sleeve itself, but rather in the tube material adjacent to one of the sleeve welds. The problem is associated with 
the residual stresses and thermal cycle associated with the sleeve welding process. Since the cracked tube material has already proven to be susceptible to PWSCC, the addition of undesirable tensile residual stresses and possible detrimental microstructural changes create an opportune situation for further PWSCC. Pierson and Stubbe 16 report that more than 50\% of explosively expanded sleeves used in Belgian reactors produced PWSCC failures in the adjacent tubing within a few months. Guidelines have been developed for sleeve materials, design, joining procedure, and subsequent residual stress relief. 18

\subsection{Outer Diameter Stress Corrosion Cracking}

\subsubsection{ODSCC in the Tube Support Plate Crevice}

ODSCC/IGA is a leading cause of PWR steam generator tube plugging in the U.S. and worldwide, and the tube support plate crevice is the predominant location for this process. Corrosion products, mainly from the tube support plate, and deposited sludge from the secondary water system eventually fill this crevice with porous material, resulting in a region of restricted secondary water flow, intermittent dryout, and concentration of corrosive species. The $\mathrm{pH}$ of the concentrated crevice may be very basic if the bulk water has a high cation/anion ratio or somewhat acidic for a low cation/anion ratio. 19 This subject is described in more detail in a subsequent paper by Millet and Welty entitled "A Review of the Current Understanding of PWR SG Crevice Chemistry."

The OD cracking observed in the tube support plate crevice is generally intergranular in nature and commonly consists of short axial cracks of varying length and depth within the crevice region. Adjacent cracks are often separated by ligaments of sound tubing material, and crack linkage can occur as ligament sections are corroded. Other more complex ODSCC crack configurations have been increasingly observed at the tube support plate crevice in recent years. For example, intergranular cellular cracking has been seen at this location in a 
number of reactors, with the extent of cracking ranging from relatively minor in tubes from the Prairie Island 20 and Asco steam generators 21 to more severe for tubes from the Sequoyah 22 and Doel $4^{23,24}$ steam generators. Cracking in all forms tends to occur more commonly in the hot leg of the $U$ tube.

The crevice is essentially inaccessible for the purpose of making in situ analyses of the local water chemistry, but numerous calculations of local chemistry have been made using computer codes such as MULTEg and MONA.25-28 Concentration factors for dissolved salts in the secondary water are predicted to approach $10^{8}$ in the crevices, and, depending upon the nature of the concentrated species, crevice pH can depart greatly from that of the secondary water. Under high cation/anion ratio conditions, $\mathrm{NaOH}$ concentrations are calculated to reach several percent, as compared with ppm levels in the bulk secondary coolant. The corresponding crevice $\mathrm{pH}$ values at operating temperatures can exceed 10 , with the neutral $\mathrm{pH}$ at $300^{\circ} \mathrm{C}$ being $5.7^{26}$ Under low cation/anion conditions, local concentration of acid sulfates or chlorides may reduce $\mathrm{pH}$ values to $<2.28$ These $\mathrm{pH}$ extremes represent aggressive environments with respect to the cracking of Alloy 600.

ODSCC/IGA at the support plate crevices is most commonly observed in the extended series of Westinghouse steam generator designs with carbon steel support plates and drilled circular holes (Models 44,51,51M, D-2, D-3, D-4, and E). These are still the dominant designs in service in the U.S. The susceptibility of these designs to ODSCC/IGA is not surprising, since their carbon steel support plates readily corrode in the secondary water environment, filling the annular crevices with corrosion product, and the LTMA Alloy 600 used for the tubes in these designs is susceptible to IGSCC. Westinghouse has addressed some of the deficiencies in their more recent steam generator designs, using thermally treated (TT) Alloy 600 tubes and broached quatrefoil Type 405 stainless steel support plates in their Model D-5. Alloy 600 TT or Alloy 690 tubes and broached 
quatrefoil Type 405 stainless steel support plates are used in the Models $\mathrm{F}$ and Delta 75 steam generators.

The improved Westinghouse designs appear to have alleviated the severe ODSCC and IGA problems seen in earlier units, although longer service times are needed to verify this. Three reactors (Catawba 2, Byron 2, and Braidwood 2) have been using the Model D-5 steam generators for the past seven to nine years with no ODSCC/IGA reported. Several of the Model F steam generators have been in service for ten years or more (Turkey Point 3 and 4, H. B. Robinson, Surrey 1 and 2, and Callaway), and again no ODSCC/IGA has been observed. 1 For all but the Callaway plant, these Model F units are replacements for earlier failed steam generators. No Delta 75 steam generators are yet in service, but the replacement units for the cracked Model D-3 steam generators in the V. C. Summer plant are to be of this design.

Combustion Engineering (CE) steam generators have used the more resistant HTMA Alloy 600 tubes from the beginning. Despite this, a majority of the CE steam generators that have been in service for more than six years have experienced at least some ODSCC/IGA, although less severe than in the Westinghouse steam generators using Alloy 600 LTMA tubes. The replacement units installed at Millstone 2 in 1992, which were built by B\&W of Canada, used Alloy $690 \mathrm{TT}$ tube material in response to this concern.

\subsubsection{ODSCC in the Tube Sheet Region}

ODSCC and IGA also commonly occur in the tube sheet region, either in the built-in crevice between the tube sheet and the tubes that was present in earlier Westinghouse designs or in the sludge pile atop the tube sheet. At either location, the process is similar to that operative in the tube support plate

crevices, with the creation of highly caustic or acidic conditions in the crevice because of local boiling and concentration effects. 
In older Westinghouse steam generator designs (up through the early Model 51 units), the roll bond sealing the tubes to the tube sheets extended only $\approx 50-75$ $\mathrm{mm}(2-3$ in.) above the bottom of the tube sheet, leaving an annular crevice of $\approx 0.2 \mathrm{~mm}(0.008 \mathrm{in}$.) in width around the unexpanded portion of the tube for the remaining length of the $530-\mathrm{mm}$ (21-in.) thick tube sheet. This crevice created a favorable environment for the concentration of impurity species, and significant ODSCC/IGA problems at the location were experienced at a number of units of this design, including Ginna, Point Beach 1 and 2, Robinson 2, Kewaunee, and Cook 1 in the U.S. and Doel 2 in Belgium, Beznau 1 and 2 in Switzerland, Ringhals 2 in Sweden, and Takahama 2 in Japan. This problem has been eliminated in more modern steam generator designs with the use of full-depth tube expansion.

However, even with these design improvements, deposition of corrosion products and sludge atop the tube sheet can still occur, particularly at locations where flow rates are low. The porous sludge deposits effectively create crevicelike regions in the vicinity of the tubes that result in local boiling and impurity concentration. 29 General wastage and pitting of the tubes can result, 30 but the more serious problem is the occurrence of severe ODSCC and IGA. 18,9,31 Residual stresses introduced by the tube expansion process appear to contribute to the cracking process in this region. The resulting RTZ cracking is commonly circumferential, for which the plugging criteria used in both the U.S. and most European countries require tube plugging for throughwall cracks. However, axial and multi-directional cracks are also commonly observed.8,32

ODSCC/IGA can also occur in the sludge-pile region above the RTZ. The situation here is very similar to that present at the tube support plate crevices filled with corrosion product and sludge. These cracks are commonly axial, but more complex multidirectional cracking has been reported in Belgian plants. 32 


\subsubsection{ODSCC/IGA in the Free Span}

The free span regions of steam generator tubes have generally been thought of as unlikely locations for significant ODSCC because of the apparent absence of crevices or other geometries favorable to the local concentration of impurity species. However, secondary-side ODSCC and IGA in the free-span region has observed a number a times over the years, and, in particular, the rupture of a steam generator tube at the Palo Verde 2 plant in March 1993 dramatized the potential for significant free-span ODSCC/IGA. 33

The free span cracking incidents observed in recent years may be divided into three categories. The first category includes those incidents in which the tube bundle geometry created a local region favorable for the concentration of impurity species. In some cases, structural occlusions produced local steam pockets (Ft. Calhoun ${ }^{34}$ and Maine Yankee ${ }^{35}$ ), and in others the impurity concentration occurred under corrosion product or sludge deposits on the tube surface (Palo Verde $2^{33}$ and Crystal River $3^{36}$ ). The second category also includes those incidents in which aggressive chemical species in the secondary water were responsible for cracking without the need for local concentration. Examples are provided by Doel $4^{23,24}$ and Farley 1,37 where significant $\mathrm{Pb}$ (and to a lesser extent $\mathrm{Cu}$ ) contamination was present.

The third category of free span cracking is the most interesting in that ODSCC occurred at a location where neither impurity concentration not contamination by aggressive species was implicated. Examples are provided by the McGuire $1989^{38}$ and $1992^{39}$ occurrences as well as the Braidwood $1^{39}$ cracking. In both reactors, the cracking apparently occurred at preexisting surface flaws, but the chemical species and the concentration mechanism responsible are not obvious. 


\subsection{Circumferential Cracking at the RTZ and Dented TSPS}

A particularly troubling recent trend has been the increasing occurrence of circumferential cracking at the RTZ on both the primary and secondary sides. Such circumferential cracks normally require plugging or sleeving upon detection, since they are difficult to reliably size, the threshold of detection for these cracks is greater in terms of size than for axial cracks, and their growth rates are difficult to predict. 40 As early as 1992, limited cracking of this type was reported at Arkansas Nuclear One Unit 2,41 and Maine Yankee plugged 358 tubes because of this degradation mode prior to $1995.40,42,43$ However, the most dramatic example of this type of failure was provided by Maine Yankee during a subsequent unscheduled shutdown and subsequent refueling outage in early 1995, when an inspection carried out during March and April revealed that more than $60 \%$ of the tubes had circumferential crack indications in the RTZ.10 All of the cracks were seen on the hot leg side of the tubes. This inspection was one of the first using the advanced Zetzec +Point ${ }^{\mathrm{TM}}$ eddy current probe, which was specifically designed to provide improved sensitivity to circumferential cracking. The decision was made to repair all 17,000 tubes in Maine Yankee using Westinghouse laser-welded sleeves, and the plant finally returned to service at 90\% power in January of 1996 after an outage of about one year.44 Even more recently, extensive circumferential RTZ PWSCC at the Salem 1 plant has resulted in a decision to replace the steam generators, 45,46 and significant circumferential PWSCC is being reported at the Braidwood 1 and Byron 1 nuclear plants ${ }^{4-49}$ as well as at Sequoyah 1, Diablo Canyon, and Callaway 1.49

Both axial and circumferential cracking has been observed at dented TSP locations at several of the same plants that have reported circumferential RTZ cracking, including Sequoyah 1, Diablo Canyon 1, and Salem 1.49 These indications are associated with minor dents and were detected using more advanced EC probes such as the Cecco probe or a rotating probe with + Point ${ }^{\mathrm{TM}}$ or 
pancake coils. The examinations suggest that the axial indications initiated at the ID and the circumferential indications at the OD. However, destructive examination at Diablo Canyon 1 determined that several of the circumferential cracks initiated at the ID.

\section{Reliability of Detection and Sizing of Flaws}

Conventional eddy-current bobbin coils are currently the principal tool utilized for detecting flaws in steam generator tubing. Multiple frequencies are used to acquire data, with the frequencies selected dependent on the tube material, geometry and inspection objectives. Currently, four different frequencies are used for detection and sizing of flaws. Optimizing one of the frequencies or finding an appropriate frequency mix for detection of small cracks is important in devising an inservice inspection (ISI). The bobbin coils allow for fast inspection rates and have been reasonably reliable for the types of flaws generally seen in the past. However, their effectiveness for some of the more recently observed flaw types, such as circumferential IGSCC or cracks in dents, is questionable. Regardless of flaw type, cracks are not generally detectable until they are $\approx 40-50 \%$ throughwall. 50 Supplemental probes of varying design (rotating-pancake-coils, pancake arrays, cross-wound coils, transmit/receive reflection coils, etc.) are employed to help resolve questionable bobbin-coil indications or generally improve inspections.

A clear need exists for quantifying the reliability of ISI methods with respect to the probability of detection (POD) of the various types of flaws and their accurate sizing. This information is necessary to assess the true state of degradation after an ISI so that the consequences of leaving degraded tubes in service over the next reactor operating cycle can be accurately assessed, as discussed below. Improvements in the POD of flaws and sizing accuracy will, in turn, require more sophisticated probes and an increased number of pulled tubes or retired steam generator sections, along with laboratory-generated cracks, 
against which to qualify procedures and techniques. One of the ISI techniques under development that shows promise for improved accuracy in sizing defects is the application of neural networks.

A standard convention in the industry is to attempt to relate ODSCC eddy current voltage amplitude to tube integrity and leakage. This approach is empirical, and the relationship between eddy current voltage amplitude and crack depth and length is relatively poor. Thus, the use of voltage amplitude for flaw detection and sizing requires a very conservative approach to data analysis and data interpretation, and one concern is the possibility of a small eddy current voltage arising from a crack with a low burst pressure. PNL has shown that burst pressure and the probability of leakage can be related to an eddy current voltage, but the correlation not yet satisfactory. In particular, no strong relationship is observed between leak rate and voltage. However, with proper assumptions, a voltage based approach may be useful for predicting potential primary-tosecondary leakage.51 It is clear that the robustness of eddy current voltage parameter and of other flaw characterization parameters and techniques must be evaluated with respect to their range of applicability.

\section{Performance-Based Steam Generator Rule and Regulatory Guide}

The U.S. Nuclear Regulatory Commission (NRC) is presently developing a "performance-based" rule and regulatory guide for steam generator tube integrity. This new rule is necessitated by the fact that current regulatory practice, which was formulated in the 1970s, is becoming outdated with the advent of substantial improvements in inspection technology and the increasing occurrence of such degradation modes as circumferential cracking, intergranular attack, and discontinuous axial cracking with interspersed intact ligaments. For at least some degradation modes, the current "rule-based" regulatory approach appears to be too conservative. 
Current regulatory practice takes a prescriptive approach under which tube plugging or repair is required when certain conditions are met. The most notable of these is that degradation depth by any process cannot, in general, exceed $40 \%$ of the tubing wall thickness. This depth was chosen to provide a factor of three safety margin against burst under operating conditions and 1.4 against burst under postulated accident conditions. It includes allowances for NDE measurement error and flaw growth between inspections (how much?) Objections to these plugging limits are based on the fact that flaw depth alone is often not best indicator of tube strength and that cracks in particular may not be inspectable to the $40 \%$ depth criterion. In response to these objections, eddy current voltage-based alternate repair criteria have been developed for ODSCC at the tube support plates and flaw length parameters on SCC in the tube expansion zone at the tube sheets. In addition, alternate plugging criteria, (based upon what?...need some words here), are being developed to deal with circumferential cracking at the RTZ.

Leak rate limits are also imposed under current regulatory practice. The primary-to-secondary leak rate cannot exceed 500 gallons per day per steam generator to guard against possible rupture of the leaking tube before shutdown. In addition, the leak rate for all steam generators in a given plant cannot exceed 1 gallon per minute to ensure that the radiological consequences of leakage during postulated accidents is within applicable limits. Leak rate limits in conjunction with effective leakage monitoring have proven to be an effective means for minimizing the frequency of tube ruptures, but significant precursor leakage may not always precede a tube rupture event.

The new performance-based rule would do away with this prescriptive and sometimes inflexible approach. The new rule and the accompanying NRC Regulatory Guide would require the development and implementation of a steam generator management program that monitors tube condition against accepted performance criteria to ensure that the tubes perform the required safety 
function over the next operating cycle. In particular, the performance criteria must ensure that the tubes have adequate structural and leakage integrity to permit safe shutdown under normal, design-basis-accident, and severe-accident conditions. Analyses must be performed to calculate overall projected leak rates over the next operating cycle for degraded tubes remaining in service. However, the specific implementation details and methodologies for the new steam generator rule are to be developed by the utilities, with the regulatory guide providing broad guidelines concerning the key considerations, parameters, and constraints that must be addressed. It is the intention of the new rule that the licensees have the flexibility to adjust the specifics of their program within the constraints of the regulatory guide guidelines to reflect new information, new NDE technology, new degradation mechanisms, and changes in flaw growth rate with NRC review and approval.

The Regulatory Guide framework supporting the new steam generator rule will include a number of key elements. First of all, it will provide guidance for developing measures to mitigate active degradation and to minimize the potential for new forms of degradation. Secondly, it will provide guidance on the development of inservice inspection programs, tube repair criteria, and leakage limit and monitoring programs. In addition, it will provide performance criteria commensurate with adequate tube structural and leakage integrity. Guidance will also be provided for performing assessments to confirm that the performance criteria adopted have been met during the previous operating cycle and that they will continue to be met during the next operating cycle. Finally, guidance will be provided on appropriate corrective actions (e.g., mitigation of active degradation mechanisms, improved ISI procedures, etc.) and for evaluating the radiological dose consequences of tube leakage during postulated accidents. The new rule is discussed in more detail in a subsequent paper by Strosnider entitled "Steam Generator Rule." 


\subsection{Degradation-Specific Management}

Implementation of the new steam generator rule and its provisions for degradation-specific management is likely to result in different acceptance/repair limits for different types of degradation at different locations. For example, flaws occurring in tubes at locations where support structures exist (e.g., axial ODSCC at the tube support plates) may be restricted from gross failure and leakage by the presence of those support structures and might therefore require less restrictive acceptance/repair limits than similar cracking in the free span. Another form of degradation that is being increasingly observed is cracking made up of numerous small crack segments with interspersed uncracked ligaments. Tubes with this type of cracking exhibit higher failure pressures and lower leak rates than would be predicted for the overall bounding crack. However, as the individual crack segments grow and the ligaments become smaller, the strengthening effect of these ligaments disappears as some stage, and the failure pressure and leak rate predictions for the overall bounding crack then apply. Thus, as long as it can be established that such cracks remain in the "infant" stage, a less demanding acceptance/repair limit might be applied them.

As the above examples illustrate, the implementation of a performance-based rule and degradation-specific management requires a detailed knowledge of the specific nature and severity of the flaws present in a given steam generator. This detailed knowledge, in turn, requires that robust methods be developed for survey inspections, so that flaws can be reliably detected and correctly classified and characterized. Only then can appropriate degradation-specific management requirements be applied to them. A subsequent paper in this session by Kupperman and Bakhtiari entitled "Computational Modeling of Eddy Current Tests" describes in detail the results of calculated simulated eddy current probe responses to typical steam generator OD tube defects. A second paper by the same authors entitled "Characterization of Flaws in a Tube Bundle Mockup for 
Reliability Studies" discusses progress to date on the development of a tube bundle mockup for the evaluation of current ISI technologies used to detect and characterize tubing degradation. Finally, an additional paper by Henry and Welty entitled "Steam Generator Tubing NDE Performance" provides a review of the current NDE technology for the ISI of steam generator tubing.

\subsection{Evaluations Based on Overall Projected Leak Rates}

Some current safety and integrity evaluations are based on calculations of overall projected leak rates over the next operating cycle for degraded tubes remaining in service. Additional information is needed in several areas to implement these evaluations. The first of these areas is once again inspection reliability, POD, and sizing accuracy. Detailed information on inspection reliability and POD will permit the true state of the generator to be estimated after ISI by including flaws that were missed because of imperfect POD. Similarly, knowledge of sizing accuracy will permit corrections in the flaw sizes obtained from ISI.

Evaluations based on calculated overall projected leak rates also require information on the nature of the specific degradation processes active in the steam generator so that the state of degradation at the end of the operating can be estimated. More specifically, information on crack initiation is needed to estimate the number of cracks that will develop during the operating cycle, and information on crack evolution and morphology will permit an estimation of the total growth of cracks present at the beginning of the cycle as well as of those that initiate during the cycle. In addition, an understanding of the crack evolution and morphology is needed to determine if small cracks and ligaments change during the cycle to produce more planar cracks by the end of the cycle.

Finally, integrity correlations are needed to relate failure pressures, failure modes, and leak rates to crack size, type and morphology. These correlations can be used to determine if cracks present in the tubes are likely to cause failure under normal or, as discussed below, accident conditions before the end of the 
operating cycle. If failure is predicted, the models can be used to estimate the resulting leak rates.

\subsection{Evaluations for Severe Accident Conditions}

The above discussions have dealt primarily with possible tube failure under normal operating conditions. However, expected tube performance under severe accident conditions (e.g., station blackout and loss of primary feedwater) must also be considered in determining the continued serviceability of a steam generator with degraded tubes. As stated above, the performance criteria must ensure that the tubes have adequate structural and leakage integrity to permit safe shutdown under normal, design-basis-accident, and severe-accident conditions.

The principal concern under a severe accident scenario is containment bypass. The steam generator tubes make up more than $50 \%$ of the surface area of the primary pressure boundary, and the failure of a significant number of tubes during a severe accident would result in an unacceptable release of radionuclides to secondary side and eventually to the environment. The new steam generator rule must conform with NRC safety goal guidance that the probability of such containment bypass be less than $10^{-6}$ per year. The Regulatory Guide will discuss how licensees are to address the severe accident risk associated with degraded steam generator tubes in order to achieve this goal.

Preliminary analyses are being performed for a hypothetical severe accident scenario in which a Westinghouse-design PWR suffers loss of primary feedwater under station blackout conditions. One of the critical questions to be answered is whether failure will occur first in the steam generator tubes, which would lead to containment bypass, or instead in the hot leg nozzle or surge line, which would not. It appears that the relative timing the various failure events is quite sensitive to the high-temperature properties of the affected structural materials and the temperature history assumed. A description of the models and methodology being developed to analyze steam generator integrity under severe accident 
conditions, as well as under accident and normal conditions, is reported in another paper in this session by Majumdar and Shack entitled "Predictions of Structural Integrity of Steam Generator Tubes Under Normal Operating, Accident, and Severe Accident Conditions." A related paper by Gorman et al. entitled "Estimating Probable Flaw Distributions in PWR Steam Generator Tubes" discusses a methodology for estimating the distributions of flaws of various types in steam generator tubes, as required, for example, in calculating the probable primary-to-secondary leakage through steam generator tubes under postulated severe accident conditions.

\section{Summary of Research Needs}

This paper has attempted to summarize the principal corrosion-related degradation processes observed in steam generator tubing and to provide the basis for and philosophy behind the new steam generator rule and Regulatory Guide. A number of research needs have been mentioned or alluded to in the course of these discussions, and these needs may be summarized as follows:

1. Because implementation of the new performance-based steam generator rule requires a detailed knowledge of the specific nature and severity of the flaws present in a given steam generator, a clear need exists for quantifying the reliability of ISI methods with respect to the POD of the various types of flaws and their accurate sizing. This information is necessary to assess the true state of degradation after an ISI so that the consequences of leaving degraded tubes in service over the next reactor operating cycle can be accurately assessed. As a part of this quantification, the robustness of the eddy current voltage parameter and of other flaw characterization parameters and techniques need to be evaluated with respect to their range of applicability.

2. The above-cited need for improved POD and flaw sizing requires more sophisticated probes and an increased number of pulled tubes or retired 
steam generator sections, along with laboratory-generated cracks, against which to qualify procedures and techniques.

3. Steam generator evaluations under the new rule based on overall projected leak rate require information on crack initiation to estimate the number of cracks that will develop during the operating cycle. In addition, information on crack evolution and morphology is needed to permit an estimation of the total growth of cracks present at the beginning of the cycle as well as of those that initiate during the cycle. This information is also needed to determine if small cracks and ligaments change during the cycle to produce more planar cracks by the end of the cycle.

4. Integrity correlations are needed to relate failure pressures, failure modes, and leak rates to crack size, type and morphology. These correlations can be used to determine if cracks present in the tubes are likely to cause failure under normal or accident conditions before the end of an operating cycle, and, if so, to estimate the resulting leak rate. 


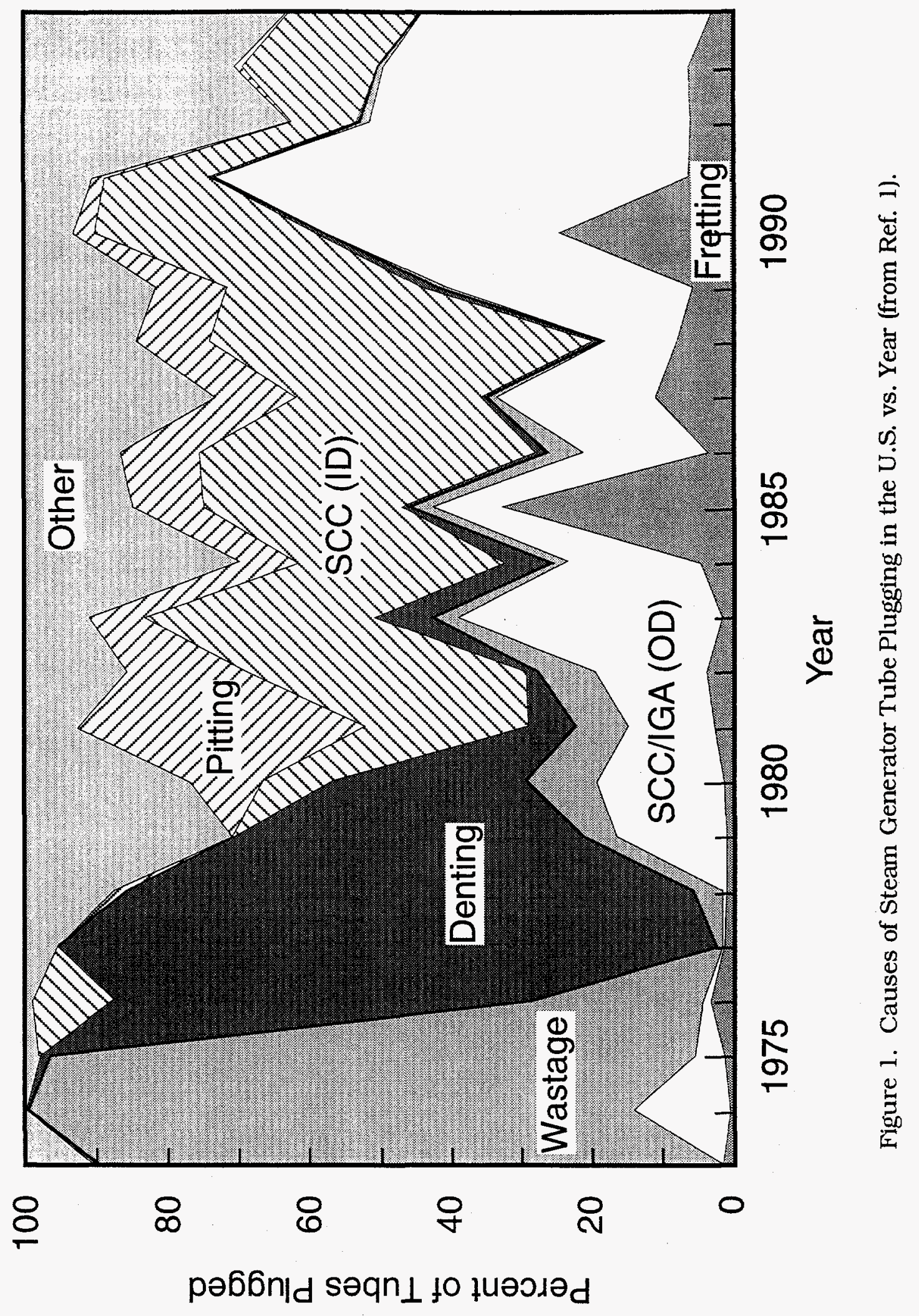




\section{References}

1. B. L. Dow, Jr., Steam Generator Progress Report, Revision 11, EPRI Research Project RP3580-06, Electric Power Research Institute, Palo Alto, CA (November 1995).

2. J. Douglas, Solutions for Steam Generators, EPRI Journal (May/June 1995), pp. 28-35.

3. J. C. Fournel, A Statistical Insight in the Suspected Relations Between PWSCC in R.T.Z. and IGASCC on TSP'S, paper \#3 presented at the EPRI Workshop on Steam Generator Secondary Side IGA/SCC, Oct. 14-15, 1993 Minneapolis, MN.

4. J. Stubbe, Alloy 600 Primary Water SCC: a User's (Belgian Electricity Board) Point of View, presented at the Alloy 600 PWSCC Experts Meeting, Arlie, France, April 6-9, 1993.

5. C. S. Welty, Jr. and J. C. Blomgren, Steam Generator Issues, pp. 1-27 to 1-36 in Proc. Fourth International Symposium on Environmental Degradation of Materials in Nuclear Power Systems-Water Reactors, Jekyll Island, GA, August 6-10, 1989, National Association of Corrosion Engineers, Houston, TX (1990).

6. C. O. Ruud and M. E. Jacobs, Residual Stresses in Roller-Expanded Steam Generator Tube Transitions, EPRI Report TR-102355, Electric Power Research Institute, Palo Alto, CA (May 1993).

7. J. A. Gorman and E. S. Hunt, Critical Factors Assessment for U-Bend and Transition Cracking, Paper 5 in Proceedings: 1985 Workshop on Primary-Side Stress Corrosion Cracking of PWR Steam Generator Tubing, EPRI NP-5158, Electric Power Research Institute, Palo Alto, CA (June 1987).

8. P. Saint Paul and G. Slama, Steam Generator Materials Degradation, pp. 39-49 in Proc. Fifth International Symposium on Environmental Degradation of Materials in Nuclear Power Systems-Water Reactors, Monterey, CA, Aug. 2529, 1991, American Nuclear Society, La Grange Park, IL (1992). 
9. R. J. Kurtz, R. A. Clark, E. R. Bradley. W. M. Bowen, P. G. Doctor, and R. H. Ferris, Steam Generator Tube Integrity Program/Steam Generator Group Project, NUREG/CR-5117, U.S. Nuclear Regulatory Commission, Washington, DC (May 1990).

10. Potential Failure of Westinghouse Steam Generator Tube Mechanical Plugs, NRC Information Notice 89-33, U.S. Nuclear Regulatory Commission, Washington, DC (March 23, 1989).

11. Failure of Westinghouse Steam Generator Tube Mechanical Plugs, NRC Bulletin 89-01, U.S. Nuclear Regulatory Commission, Washington, DC (May 15, 1989).

12. Failure of Westinghouse Steam Generator Tube Mechanical Plugs, NRC Bulletin 89-01, Supplement 1, U.S. Nuclear Regulatory Commission, Washington, DC (November 14, 1990).

13. Failure of Westinghouse Steam Generator Tube Mechanical Plugs, NRC Bulletin 89-01, Supplement 2, U.S. Nuclear Regulatory Commission, Washington, DC (June 28, 1991).

14. Unanticipated Crack in a Particular Heat of Alloy 600 Used for Westinghouse Mechanical Plugs for Steam Generator Tubes, NRC Information Notice 94-87, U.S. Nuclear Regulatory Commission, Washington, DC (December 22, 1994).

15. Potential for Stress Corrosion Cracking in Steam Generator Tube Plugs Supplied by Babcock and Wilcox, NRC Information Notice 89-65, U.S. Nuclear Regulatory Commission, Washington, DC (September 8, 1989).

16. E. Pierson and J. Stubbe, SCC Testing of Steam Generator Tubes Repaired by Welded Sleeves, pp. 697-705 in Proc. Sixth International Symposium on Environmental Degradation of Materials in Nuclear Power Systems-Water Reactors, San Diego, CA, Aug. 1-5, 1993, R. E. Gold and E. P. Simonen, eds., The Minerals, Metals, and Materials Society, Warrendale, PA (1993).

17. Potential Failure of Steam Generator Tubes with Kinetically Welded Sleeves, NRC Information Notice 94-05, U.S. Nuclear Regulatory Commission, Washington, DC (January 19, 1994). 
18. E. S. Hunt and J. A. Gorman, Guidelines for PWR Steam Generator Tubing Specifications and Repair. Volume 3: Steam Generator Tube Sleeving: Design, Specification, and Procurement Checklist, EPRI NP-6743-L, Electric Power Research Institute, Palo Alto, CA (February 1991).

19. J. P. N. Paine, S. A. Hobart, and S. G. Sawochka, Predicting Steam Generator Crevice Chemistry, pp. 739-744 in Proc. Fifth International Symposium on Environmental Degradation of Materials in Nuclear Power Systems-Water Reactors, Monterey, CA, Aug. 25-29, 1991, American Nuclear Society, La Grange Park, IL (1992).

20. R. P. Pearson and S. Lappegaard, Use of Inhibitors for Secondary Side IGA/SCC at Prairie Island, presented at the EPRI Workshop on Steam Generator Secondary Side IGA/SCC, Minneapolis, MN, October 14-15, 1993.

21. A M. Lancha, D. Gómez-Briceño, and E. López-Toribio, PWSCC and IGA/SCC in Tubes Pulled out from Operating Steam Generators, paper A2 in Proc. of the IAEA Specialists Meeting on Steam Generator Problems and Replacement, Madrid, Spain, December 13-16, 1993.

22. D. E. Hughes, Sequoyah Nuclear Plant Tube Pull Results, presented at the EPRI Workshop on Steam Generator Secondary Side IGA/SCC, Minneapolis, MN, October 14-15, 1993.

23. J. Stubbe, C. Laire, and E. Pierson, Secondary Side Corrosion at Doel 4Mechanisms and Effects of Phosphate Injection, presented at the EPRI Workshop on Steam Generator Secondary Side IGA/SCC, Minneapolis, MN, October 14-15, 1993.

24. C. Laire, J. Stubbe, and E. Pierson, Doel 4: Secondary Side Corrosion Mechanisms and Effects of Phosphate Injection, paper A3 in Proc. of the IAEA Specialists Meeting on Steam Generator Problems and Replacement, Madrid, Spain, December 13-16, 1993. 
25. J. P. N. Paine, S. A. Hobart, and S. G. Sawochka, Predicting Steam Generator Crevice Chemistry, pp. 739-744 in Proc. Fifth International Symposium on Environmental Degradation of Materials in Nuclear Power Systems-Water Reactors, Monterey, CA, Aug. 25-29, 1991, American Nuclear Society, La Grange Park, IL (1992).

26. C. E. Shoemaker and J. P. N. Paine, Modeling Nuclear Steam Generator Environments, pp. 237-242 in Proc. Third International Symposium on Environmental Degradation of Materials in Nuclear Power systems-Water Reactors, Traverse City, MI, August 30-September 3, 1987, G. J. Theus and J. R. Weeks, eds., The Metallurgical Society, Warrendale, PA (1988).

27. A. Kishida, H. Takamatsu, H. Kitamura, S. Isobe, K. Onimura, K. Arioka, Y. Hattori, T. Arai, and M. Sato, The Causes and Remedial Measures of Steam Generator Tube Intergranular Attack in Japanese PWR, pp. 465-471 in Proc. Third International Symposium on Environmental Degradation of Materials in Nuclear Power systems-Water Reactors, Traverse City, MI, August 30September 3, 1987, G. J. Theus and J. R. Weeks, eds., The Metallurgical Society, Warrendale, PA (1988).

28. A. Stutzmann and F. Nordmann, Hideout Return in EDF Units, presented at the EPRI Workshop on Steam Generator Secondary Side IGA/SCC, Oct. 14-15, 1993 Minneapolis, MN.

29. P. J. Millet and J. M. Fenton, A Detailed Model of Localized Concentration Processes in Porous Deposits of SG's, pp. 745-751 in Proc. Fifth International Symposium on Environmental Degradation of Materials in Nuclear Power Systems-Water Reactors, Monterey, CA, Aug. 25-29, 1991, American Nuclear Society, La Grange Park, IL (1992). 
30. F. Gonzalez and P. Spekkens, Corrosion of Inconel 600 under Steam Generator Sludge Piles, pp. 7-108 to 7-120 in Proc. Fourth International Symposium on Environmental Degradation of Materials in Nuclear Power Systems-Water Reactors, Jekyll Island, GA, August 6-10, 1989, National Association of Corrosion Engineers, Houston, TX (1990).

31. P. LeMaire, Current Status (1993) of ODSCC at EDF Plants, presented at the EPRI Workshop on Steam Generator Secondary Side IGA/SCC, Minneapolis, MN, October 14-15, 1993.

32. C. Leblois, Belgian Steam Generator Experience: The Whole Picture, Nucl. Eng. Int., Vol. 32 (May 1992), pp. 25-33.

33. K. Sweeney and M. Melton, Free-Span IGA/SCC at the Palo Verde Nuclear Generating Station, presented at the EPRI Workshop on Steam Generator Secondary Side IGA/SCC, Minneapolis, MN, October 14-15, 1993.

34. K. R. Craig, Failure Analysis of Tube R2OL84, B Steam Generator, Ft. Calhoun, in Proc. 1985 EPRI Workshop on Remedial Actions for Secondary-Side Intergranular Corrosion, EPRI NP-4929, Electric Power Research Institute, Palo Alto, CA (December 1986), pp. A6-1 to A6-14.

35. Recent Incidents Involving Rapid Increases in Primary-to-Secondary Leak Rate, NRC Information Notice 91-43, U.S. Nuclear Regulatory Commission, Washington, DC (July 5, 1991).

36. P. A. Sherburne, K. R. Redmond, and L. P. Sykes, Laboratory Examinations of

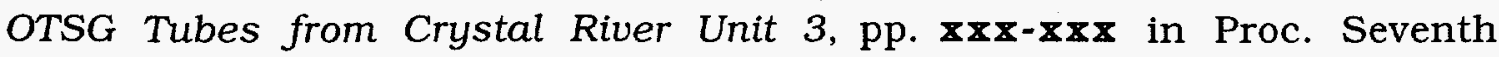
International Symposium on Environmental Degradation of Materials in Nuclear Power Systems-Water Reactors, need complete reference.

37. F. D. Hundley, Examination of Farley Unit-1 Hot Leg Steam Generator Tube, presented at the EPRI Workshop on Steam Generator Secondary Side IGA/SCC, Minneapolis, MN, October 14-15, 1993.

38. G. A. Murphy, Selected Safety-Related Events, Nucl. Safety, Vol. 30, No. 4 (October-December 1989), pp. 557-558. 
39. Operational Experience on Steam Generator Tube Leaks and Tube Ruptures, NRC Information Notice 94-62, U.S. Nuclear Regulatory Commission, Washington, DC (August 30, 1994).

40. Circumferential Cracking of Steam Generator Tubes, NRC Generic Letter 9503, U. S. Nuclear Regulatory Commission, Washington, DC (April 28, 1995).

41. Operation with Steam Generator Tubes Seriously Degraded, NRC Information Notice 92-80, U.S. Nuclear Regulatory Commission, Washington, DC (December 7, 1992).

42. Inservice Inspection Deficiencies Result in Severely Degraded Steam Generator Tubes, NRC Information Notice 94-88, U.S. Nuclear Regulatory Commission, Washington, DC (December 23, 1994).

43. The big sleeve-Maine Yankee opts not to replace, Nucl. Eng. Int. Vol. 40 (October 1995), pp. 36-38.

44. Maine Yankee Back on Line at Reduced Power Level, Nucleonics Week, Vol. 37, No. 3 (Jan. 18, 1996), p. 7.

45. Salem-1 Steam Generator Replete with Potential New Crack Type, Nucleonics Week, Vol. 37, No. 10 (March 7, 1996), p. 1.

46. Salem-1 Steam Generator Replete with Potential New Crack Type, Nucleonics Week, Vol. 37, No. 22 (May 30, 1996), p. 5.

47. ComEd Disputes Braidwood Tube Pull with NRC as More Byron Flaws Found, Nucleonics Week, Vol. 37, No. 17 (April 25, 1996), p.4.

48. Braidwood Outage Pending?, Nucleonics Week, Vol. 37, No. 21 (May 23, 1996), p.9.

49. Results of Steam Generator Tube Examinations, NRC Information Notice 9638, U.S. Nuclear Regulatory Commission, Washington, DC (June 21, 1996).

50. J. Guerra and R. L. Tapping, Working Session 2: Tubing Inspection, Proceedings of the CNRA/CSNI Workshop on Steam Generator Tube Integrity in Nuclear Power Plants, October 30-November 2, 1995, Oak Brook, IL, NUREG/CP-xxxx, pp. 299-304 (in press). 
51. Voltage-Based Interim Plugging Criteria for Steam Generator Tubes, NUREG1477 (draft report for comment), U.S. Nuclear Regulatory Commission, Washington, DC (June 1993).

\section{DISCLAIMER}

This report was prepared as an account of work sponsored by an agency of the United States Government. Neither the United States Government nor any agency thereof, nor any of their employees, makes any warranty, express or implied, or assumes any legal liability or responsibility for the accuracy, completeness, or usefulness of any information, apparatus, product, or process disclosed, or represents that its use would not infringe privately owned rights. Reference herein to any specific commercial product, process, or service by trade name, trademark, manufacturer, or otherwise does not necessarily constitute or imply its endorsement, recommendation, or favoring by the United States Government or any agency thereof. The views and opinions of authors expressed herein do not necessarily state or reflect those of the United States Government or any agency thereof. 